The Israeli Journal of Aquaculture - Bamidgeh, IJA.72.2020.1119149, 11 pages

CCBY-NC-ND-4.0 • https://doi.org/10.46989/001c.21407

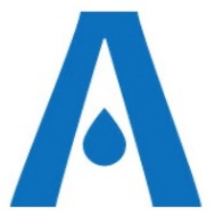

The $I J A$ is a peer-reviewed open-access, electronic journal, freely available without charge to users

Produced by the AquacultureHub non-profit Foundation Sale of $I J A$ papers is strictly forbidden

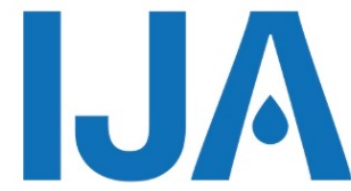

\title{
Plesiomonas shigelloides, a potential pathogen of enteritis in Ictalurus punctatus
}

\section{Huicong Wang ${ }^{1 \#}$, Ying Gu2,3\#, Huihua Zhou2,3, Jun Chen ${ }^{1}$, Minghua Wang ${ }^{4}$, Hucheng Jiang ${ }^{4}$, Haipeng $\mathrm{Cao}^{2,3 *}$}

${ }^{1}$ Department of Animal Husbandry \& Veterinary Medicine, Jiangsu Vocational College of Agriculture and Forestry, Jurong Jiangsu 212400, P.R. China.

${ }^{2}$ National Pathogen Collection Center for Aquatic Animals, Shanghai Engineering Research Center of Aquaculture, Shanghai Ocean University, Shanghai 201306, P.R. China.

${ }^{3}$ Key Laboratory of Freshwater Fishery Germplasm Resources, Ministry of Agriculture of P. R. China, Shanghai 201306, P.R. China.

${ }^{4}$ Jiangsu Freshwater Fisheries Research Institute, Nanjing Jiangsu 210017, P.R. China.

Key words: Ictalurus punctatus, Plesiomonas shigelloides, Enteritis, Potential pathogen

\begin{abstract}
Enteritis has resulted in large economic losses in channel catfish aquaculture. Yet only scarce information is available on Plesiomonas shigelloides as a causal agent for this disease. In this study, a virulent strain, temporarily named BD1, was isolated from diseased channel catfish suffering from enteritis, and was identified as $P$. shigelloides through molecular and phenotypic methods. A phylogenetic tree was also constructed to determine its taxonomic position. In addition, the BD1 isolate has developed multiple resistances to aminoglycosides, amphenicols, quinolones, tetracyclines and sulfonamides drugs for veterinary uses in aquaculture as revealed when screened against a range of common antibiotics. To the best of our knowledge, this is the first report of $P$. shigelloides as a potential pathogen of enteritis in channel catfish.
\end{abstract}

* Corresponding author. Tel.: +862161900453, fax: +862161900452, e-mail:

hpcao@shou.edu.cn; \#authors contributed equally to this work. 


\section{Introduction}

Channel catfish Ictalurus punctatus is widely cultivated in many countries such as America, Canada, China and Mexico (Liu et al., 2006; Zhang et al., 2019). Especially in China, with the rapid development of farming techniques, the channel catfish has become one of the most important commercial freshwater fish species and has brought a great profit in recent years (Zhang et al., 2019). Its production has increased to over 230,000 tons in 2018 (Ministry of Agriculture and Rural Affairs of China, 2019). However, under intensive culture, this industry has been seriously affected by bacterial diseases (Mohammed et al., 2018). Thus, more attention should be given to bacteriosis to make further development of this industry.

Enteritis, characterized by intestinal hyperemia and inflammation, is one of the most important infectious bacterial diseases in channel catfish aquaculture (Wu et al., 2000) and usually results in a high mortality of over $90 \%$ (Xie et al., 2019). So far, several bacterial pathogens such as Aeromonas punctata, Aeromonas veronii, Enterobacter aerogenes and Stenotrophomonas maltophilia have been reported to cause this disease (Wu et al., 2000; Geng et al., 2006; Huang et al., 2010; Cao et al., 2017). Plesiomonas shigelloides is a Gram-negative, rod-shaped, motile bacterium which is widely distributed in freshwater (Khardori et al., 1988; Ekundayo et al., 2020), and its occurrence in clinical infections is usually found in warm waters especially in farming waters with temperatures of 25 to $370 \mathrm{C}$ and $\mathrm{pH}$ values of 5 to 8 (Liu et al., 2015). However, little information is available on Plesiomonas shigelloides as a causal agent for enteritis in channel catfish.

The aim of this study is to characterize the phenotype, taxonomic position and antibiotic susceptibility of $P$. shigelloides pathogen isolated from enteritis-infected channel catfish. As far as we know, this is the first report of enteritis caused by $P$. shigelloides in channel catfish.

Channel catfish samples

\section{Materials and Methods}

Twenty diseased channel catfish averaging 753.0 $\pm 5.7 \mathrm{~g}$ suffering from enteritis were sampled from a channel catfish farm with a disease morbidity of $80 \%$ and water quality parameters of $\mathrm{pH} 7.80,0.20 \mathrm{mg} \mathrm{L}^{-1}$ total ammonia, $0.01 \mathrm{mg} \mathrm{L}^{-1}$ nitrite and $5.61 \mathrm{mg} \mathrm{L}^{-1}$ dissolved oxygen in Yancheng, Jiangsu China during May 2019. This farm had 15 acres of ponds with channel catfish stocked at an initial rearing density of 9100 juveniles per acre and fed pellet diets at a rate of $3 \%$ of body weight with 3 times per day. Diseased samples were placed in sterile bags, kept in ice and transported to the laboratory according to Zeng et al. (2009).

Confirmation of the pathogen

Each sampled diseased channel catfish was externally disinfected with $75 \%$ alcohol and dissected according to Zhu et al. (2001). To verify the potential pathogens, a squash of organs (intestine, liver, kidney, muscle, gill) were made and carefully examined for parasites under the microscope as described by Feng et al. (2019). Meanwhile, the virological examination was also conducted as described by Huang et al. (2013). Briefly, the homogenate of organs (intestine, liver, kidney, muscle, gill) was made and filtered through $0.22-\mu \mathrm{m}$-pore-size membrane filter to remove bacteria. Two aquaria of 10 healthy fish were injected muscularly with $0.2 \mathrm{~mL}$ of each bacteria-free organ filtrate. Another two aquaria of 10 healthy fish, which were exposed to the same experimental conditions and injected muscularly with $0.2 \mathrm{~mL}$ of normal saline, served as the control. Experimental fish were kept at $30^{\circ} \mathrm{C}$ without water change. The mortality and any visible changes of the experimental fish were recorded every day for 15 days. In addition, besides the liver, kidney samples of each diseased fish, a section of $0.1 \mathrm{~g}$ of affected intestine sample was aseptically cut and rinsed three times with sterile nine-salt solution (Olsson et al., 1992), then was separately homogenized in sterile nine-salt solution and followed by serial tenfold dilution directly streaked onto nutrient agar (NA) plates (Sinopharm Chemical Reagent Co., Ltd.) as recommended by Xu et al. (2008) and Cao et al. (2017). After incubation for $24 \mathrm{~h}$ at $30^{\circ} \mathrm{C}$, the dominant uniform isolates were purified by streaking and re-streaking onto NA plates. Only the dominant isolates with dense virtually pure culture growth on NA plates 
were obtained according to different colony shape, colony color and colony size as recommended by $\mathrm{Xu}$ et al. (2008) and Orozova et al. (2012) and were stored at $-80^{\circ} \mathrm{C}$ supplemented with $15 \%$ glycerol according to Zhang et al. (2018). The pure isolates were inoculated onto an NA plate, incubated at $28^{\circ} \mathrm{C}$ for $24 \mathrm{~h}$, and washed with sterile normal saline into a sterile tube. Their cell densities were determined by counting colony forming units after a ten-fold serial dilution in sterile saline as described by Zhu et al. (2001). Induced infection of the pure isolates was performed according to Cao et al. (2017). Briefly, two aquaria of ten healthy fish were challenged by intraperitoneal injection as recommended by Xu et al. (1988) with $0.2 \mathrm{~mL}$ of the isolate at a concentration of $2.6 \times 10^{7}$ CFU $\mathrm{mL}^{-1}$. Another two aquaria of ten healthy fish exposed to the same experimental conditions and injected intraperitoneally $0.2 \mathrm{~mL}$ of normal saline remained unchallenged and served as control. The experimental fish were kept at $30^{\circ} \mathrm{C}$ and observed daily for seven days without feeding and water change. Dead fish were immediately removed to reisolate and identify the challenge isolate as described above to confirm if the mortality was caused by the challenge isolate.

Identification of the pathogen

Molecular identification

The genomic DNA was extracted from the pathogenic isolate using the TIANamp DNA Kit (Tiangen Biotech. Co., Ltd.). Its 16S rRNA gene was amplified by PCR according to Chen et al. (2012) and was sequenced by ABI 3730 XL DNA Sequencer (Applied Biosystems, USA). A homology search was performed in the National Centre for Biotechnology Information (NCBI) database for 16S rRNA gene sequences using the Basic Local Alignment Search Tool (BLAST) program. A phylogenetic tree from the near complete 16S rRNA gene sequence of the isolate and its homologous sequences was constructed using the neighbour-joining method.

Phenotypic identification

The pathogenic isolate was identified phenotypically by API 32GN system recommended by Altwegg et al. (1987), where the isolate BD1 was grown on NA plates at $28^{\circ} \mathrm{C}$ for $24 \mathrm{~h}$, and the bacterial suspension was then used to inoculate the API 32GN test strips (Biomerieux, France) following the manufacturer's instruction. The plate was incubated at $37^{\circ} \mathrm{C}$ and observed after $18 \mathrm{~h}$ for checking against the API identification index and database. Information related to $P$. shigelloides previously reported (Wang et al., 2013; Cao et al., 2007) serves as a reference.

Bacterial virulence assay

The experiment was conducted in strict accordance with the Regulations on Experimental Animals Administration of China (Publication No. 676). Bacterial virulence was examined by experimentally infecting healthy channel catfish. One hundred healthy channel catfish averaging $75.2 \pm 1.3 \mathrm{~g}$ were obtained from a channel catfish farm in Hubei China. The experimental fish were acclimated in ten replicate aquaria (ten fish per aquarium) supplied with $100 \mathrm{~L}$ of aerated filtered farming water at $30^{\circ} \mathrm{C}$ for 14 days. Prior to the bacterial virulence assay the pathogenic isolate was inoculated onto NA plate, incubated at $30^{\circ} \mathrm{C}$ for $24 \mathrm{~h}$, then washed with normal saline into a sterile tube. Its cell density was determined by counting colony forming units after a ten-fold serial dilution in sterile saline as described by Zhu et al. (2001). Two replicates of ten healthy fish were challenged by intraperitoneal injection as recommended by Xu et al. (1988) and Cao et al. (2017) with $0.2 \mathrm{~mL}$ of the pathogenic isolate at a concentration of $2.6 \times 10^{5} \mathrm{CFU} \mathrm{mL}^{-1}$ to

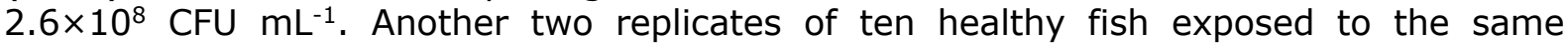
experimental conditions and injected intraperitoneally $0.2 \mathrm{~mL}$ of normal saline remained unchallenged and served as control. The experimental fish were kept at $30^{\circ} \mathrm{C}$ and observed daily for seven days without feeding and water change. Any dead fish were immediately removed and sampled to re-isolate and confirm if the mortality was caused specifically by the challenge isolate according to Liu et al. (2006). Briefly, dead fish were sampled to reisolate the challenge isolate which was confirmed phenotypically and molecularly as described above. The mean lethal dose $\left(L_{50}\right)$ value is calculated using the linear regression method as recommended by Spielmann et al. (1999).

Antibiotic susceptibility assay

The Israeli Journal of Aquaculture - Bamidgeh • IJA.73.2021.1119149 
The antibiotic susceptibility of the pathogenic isolate was assayed on NA plates using the Kirby-Bauer disk diffusion method as recommended by Yang et al. (2014). Twenty-one antibiotic discs were acquired from Hangzhou Binhe Microorganism Reagent Co., Ltd.. The zones of inhibition against the isolate were measured after a $24 \mathrm{~h}$ incubation period at $28^{\circ} \mathrm{C}$, and its susceptibility to antibiotics was determined according to the manufacturer's guidelines.

Identification of the pathogen

\section{Results}

No parasites were found in the diseased channel catfish, and all of the experimental fish challenged with the bacteria-free organ filtrate survived with no visible changes (data not shown), indicating that this disease was not caused by parasites or viruses. A total of eight dominant isolates, temporarily numbered from BD1 to BD8, were recovered from diseased fish, and only isolate BD1, which could be isolated from intestine, liver, kidney of all the sampled fish, was confirmed as the pathogen for this disease according to Koch's postulate: (i) The BD1 isolate could be isolated from diseased channel catfish. (ii) The death of the experimental fish was increased gradually over time after the challenge with isolate BD1. $30 \%-100 \%$ of the challenged fish died at an $\mathrm{LD}_{50}$ value of $2.42 \times 10^{6} \mathrm{CFU} \mathrm{mL}^{-1}$ (Table 1) and exhibited signs of intestinal hyperemia and inflammation similar to that seen in the originally diseased channel catfish (Figure 1), which was consistent with the clinical symptoms of bacterial enteritis in channel catfish reported by Wu (2000). No clinical signs or mortality are noted in the control channel catfish. (iii) The BD1 isolate could be reisolated from experimentally dead fish, which was determined through phenotypical and molecular identification. These findings demonstrated that isolate BD1 was the causative agent of this disease.

Table 1 Cumulative mortality of experimental channel catfish infected by isolate BD1.

\begin{tabular}{|c|c|c|c|c|c|c|c|c|c|c|c|}
\hline \multirow{2}{*}{ Group } & \multirow{2}{*}{$\begin{array}{c}\text { Concentration } \\
\left(\text { CFU } \mathrm{mL}^{-1}\right)\end{array}$} & \multirow{2}{*}{$\begin{array}{l}\text { Fish } \\
\text { no. }\end{array}$} & \multicolumn{7}{|c|}{ Dead fish no. on day after challenge } & \multirow{2}{*}{$\begin{array}{c}\text { Average } \\
\text { cumulative } \\
\text { mortality } \\
(\%)\end{array}$} & \multirow{2}{*}{$\begin{array}{l}\text { LD }_{50} \text { value } \\
\text { (CFU } \mathrm{mL}^{-1} \text { ) }\end{array}$} \\
\hline & & & 1 & 2 & 3 & 4 & 5 & 6 & 7 & & \\
\hline \multirow[b]{2}{*}{ Control } & \multirow[b]{2}{*}{0} & 10 & 0 & 0 & 0 & 0 & 0 & 0 & 0 & \multirow[b]{2}{*}{0} & \multirow{10}{*}{$2.42 \times 10^{6}$} \\
\hline & & 10 & 0 & 0 & 0 & 0 & 0 & 0 & 0 & & \\
\hline \multirow{2}{*}{ Treatment 1} & \multirow{2}{*}{$2.6 \times 10^{5}$} & 10 & 0 & 2 & 1 & 0 & 0 & 0 & 0 & \multirow[b]{2}{*}{30} & \\
\hline & & 10 & 1 & 1 & 1 & 0 & 0 & 0 & 0 & & \\
\hline \multirow[b]{2}{*}{ Treatment 2} & \multirow[b]{2}{*}{$2.6 \times 10^{6}$} & 10 & 2 & 1 & 1 & 0 & 0 & 0 & 0 & \multirow[b]{2}{*}{40} & \\
\hline & & 10 & 1 & 1 & 1 & 1 & 0 & 0 & 0 & & \\
\hline \multirow[b]{2}{*}{ Treatment 3} & \multirow[b]{2}{*}{$2.6 \times 10^{7}$} & 10 & 2 & 3 & 1 & 1 & 1 & 0 & 0 & \multirow[b]{2}{*}{80} & \\
\hline & & 10 & 3 & 1 & 2 & 2 & 0 & 0 & 0 & & \\
\hline \multirow[b]{2}{*}{ Treatment 4} & \multirow[b]{2}{*}{$2.6 \times 10^{8}$} & 10 & 5 & 2 & 3 & 0 & 0 & 0 & 0 & \multirow[b]{2}{*}{100} & \\
\hline & & 10 & 4 & 4 & 2 & 0 & 0 & 0 & 0 & & \\
\hline
\end{tabular}



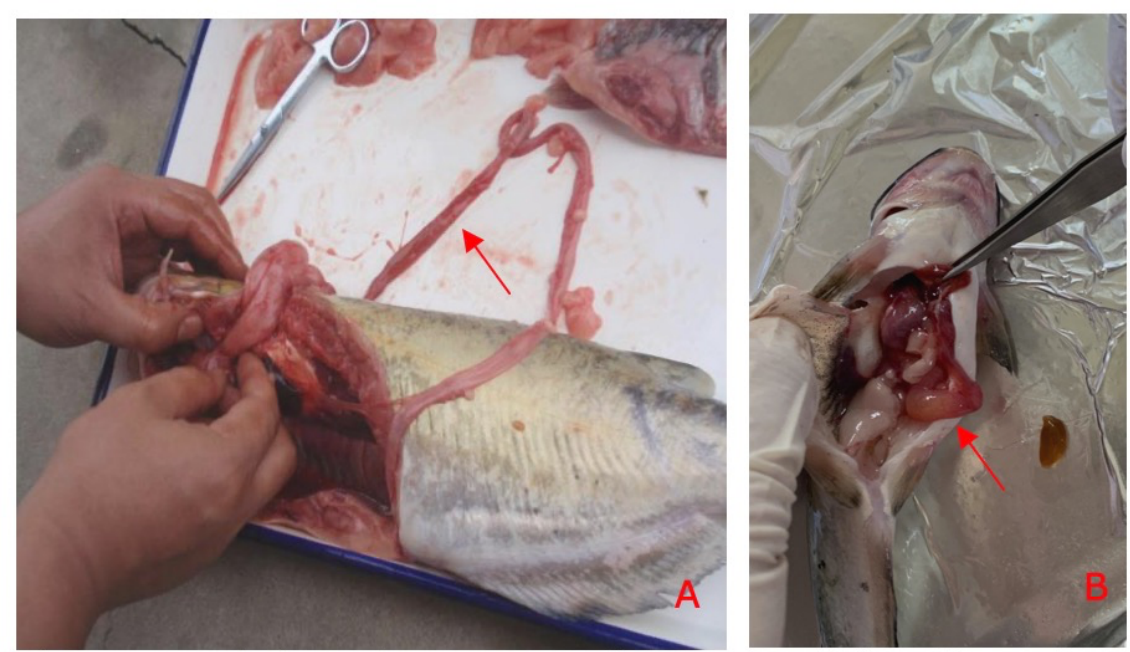

Figure 1 Pathological symptoms of channel catfish suffering from enteritis. (A) Naturally affected fish. (B) Experimental fish challenged with isolate BD1. Arrows show intestinal hyperemia and inflammation.

\section{Identification of the pathogen}

Isolate BD1 was identified by molecular and phenotypic methods as $P$. shigelloides. Its near complete $16 \mathrm{~S}$ rRNA gene sequence (1400 nucleotides) was submitted to GenBank database with the accession no. MT250047. A similarity of $99 \%$ to $100 \%$ is observed in the 16S rRNA gene sequence between the BD1 isolate and other $P$. shigelloides isolates from the GenBank database. The phylogenetic tree indicates that the BD1 isolate is identified as a $P$. shigelloides strain (Figure 2). Besides, isolate BD1 was also confirmed by the phenotypic features as $P$. shigelloides (Table 2) with $100 \%$ identity compared to the reference strain. No parasites and viruses were detected in the diseased channel catfish from which isolate BD1 was isolated.

Antibiotic susceptibility of the pathogen

The antibiotic susceptibility of isolate BD1 is shown in Table 3. The data indicate that isolate BD1 is sensitive to furazolidone, but resistant to amoxicillin, cefotaxime, cephradine, chloramphenicol, ciprofloxacin, clindamycin, doxycycline, enrofloxacin, erythromycin, florfenicol, kanamycin, levofloxacin, neomycin, norfloxacin, oxacillin, penicillin, rifampicin, streptomycin, sulfisoxazole and tobramycin. This suggests that isolate BD1 has developed multiple resistances to aminoglycosides, amphenicols, quinolones, tetracyclines and sulfonamides drugs used in aquaculture. 


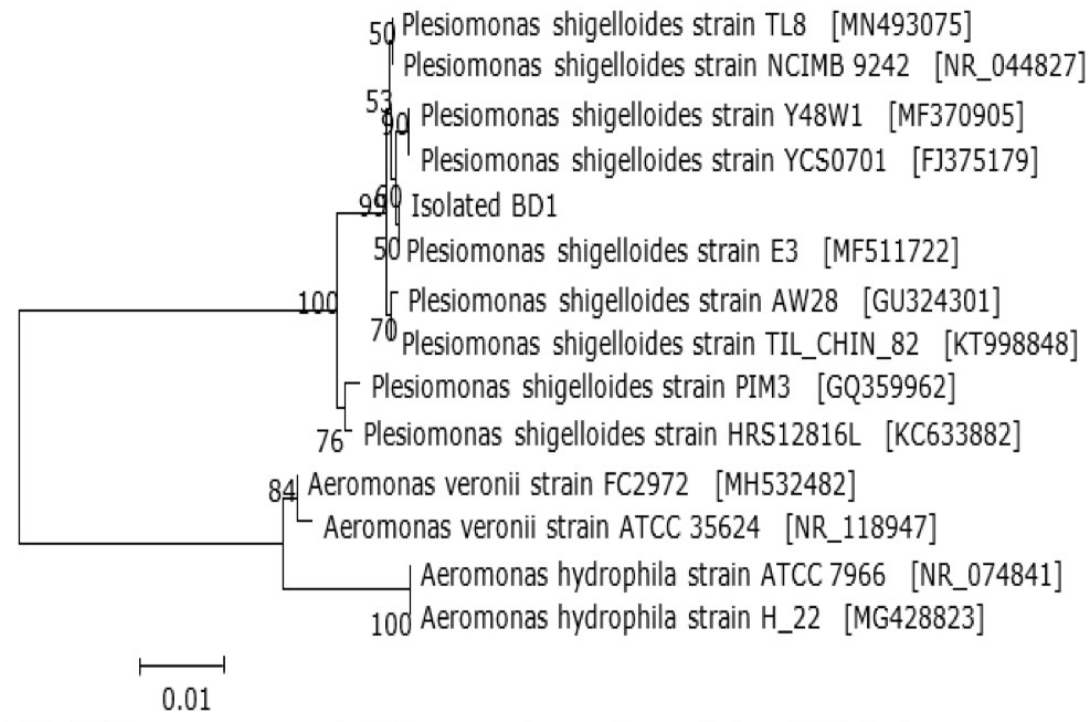

Figure $2 \mathrm{~A} 16 \mathrm{~S}$ rRNA gene tree of 13 known bacteria and the BD1 isolate constructed using the neighbor-joining method. The bootstrap values (\%) are shown besides the clades, accession numbers are indicated beside the names of strains, and scale bars represent distance values.

Table 2 Phenotypic characterization of isolate BD1.

\begin{tabular}{|c|c|c|}
\hline & \multicolumn{2}{|l|}{ Reaction } \\
\hline & Isolate BD1 & P. shigelloides ${ }^{a}$ \\
\hline Rhamnose & $\mathrm{R}^{-}$ & $\mathrm{R}^{-}$ \\
\hline N-Acetyl-glucosamine & $\mathrm{R}^{+}$ & $\mathrm{R}^{+}$ \\
\hline Ribose & $\mathrm{R}^{+}$ & $\mathrm{R}^{+}$ \\
\hline Inositol & $\mathrm{R}^{+}$ & $\mathrm{R}^{+}$ \\
\hline Saccharose & $\mathrm{R}^{-}$ & $\mathrm{R}^{-}$ \\
\hline Maltose & $\mathrm{R}^{+}$ & $\mathrm{R}^{+}$ \\
\hline Itaconate & $\mathrm{R}^{-}$ & $\mathrm{R}^{-}$ \\
\hline Suberate & $\mathrm{R}^{-}$ & $\mathrm{R}^{-}$ \\
\hline Malonate & $\mathrm{R}^{-}$ & $\mathrm{R}^{-}$ \\
\hline Acetate & $\mathrm{R}^{-}$ & $\mathrm{R}^{-}$ \\
\hline DL-Lactate & $\mathrm{R}^{-}$ & $\mathrm{R}^{-}$ \\
\hline L-Alanine & $\mathrm{R}^{-}$ & $\mathrm{R}^{-}$ \\
\hline 5-Keto-gluconate & $\mathrm{R}^{-}$ & $\mathrm{R}^{-}$ \\
\hline Glycogen & $\mathrm{R}^{-}$ & $\mathrm{R}^{-}$ \\
\hline 3-Hydroxy-benzoate & $\mathrm{R}^{-}$ & $\mathrm{R}^{-}$ \\
\hline L-Serine & $\mathrm{R}^{-}$ & $\mathrm{R}^{-}$ \\
\hline Mannitol & $\mathrm{R}^{-}$ & $\mathrm{R}^{-}$ \\
\hline D-Glucose & $\mathrm{R}^{+}$ & $\mathrm{R}^{+}$ \\
\hline Salicin & $\mathrm{R}^{-}$ & $\mathrm{R}^{-}$ \\
\hline D-Melibiose & $\mathrm{R}^{-}$ & $\mathrm{R}^{-}$ \\
\hline L-Arabinose & $\mathrm{R}^{-}$ & $\mathrm{R}^{-}$ \\
\hline L-Fucose & $\mathrm{R}^{-}$ & $\mathrm{R}^{-}$ \\
\hline
\end{tabular}

The Israeli Journal of Aquaculture - Bamidgeh • IJA.73.2021.1119149 
D-Sorbitol

Propionate

Caprate

Valerate

Citrate

Histidine

2-Keto-gluconate

3-Hydroxy-butyrate

4-Hydroxy-benzoate

L-Proline
$\mathrm{R}^{-}$

$\mathrm{R}^{-}$

$\mathrm{R}^{-}$

$\mathrm{R}^{-}$

$\mathrm{R}^{-}$

$\mathrm{R}^{-}$

$\mathrm{R}^{-}$

$\mathrm{R}^{-}$

$\mathrm{R}^{-}$

$\mathrm{R}^{+}$
$\mathrm{R}^{-}$

$\mathrm{R}^{-}$

$\mathrm{R}^{-}$

$\mathrm{R}^{-}$

$\mathrm{R}^{-}$

$\mathrm{R}^{-}$

$\mathrm{R}^{-}$

$\mathrm{R}^{-}$

$\mathrm{R}^{-}$

$\mathrm{R}^{+}$

$\mathrm{R}^{+}$: positive reaction; $\mathrm{R}^{-}$: negative reaction.

aThe reference strain's data are in accordance with those previously reported (Wang et al., 2013; Cao et al., 2007).

Table 3 Susceptibility of isolate BD1 to antibiotics.

\begin{tabular}{|c|c|c|}
\hline Antibiotics & Content ( $\mu \mathrm{g} / \mathrm{disc})$ & $\begin{array}{l}\text { Inhibition zone diameter } \\
(\mathrm{mm})\end{array}$ \\
\hline Amoxicillin & 20 & $0 \pm 0^{R}$ \\
\hline Cefotaxime & 30 & $0 \pm 0^{R}$ \\
\hline Cephradine & 30 & $0 \pm 0^{R}$ \\
\hline Chloramphenicol & 30 & $0 \pm 0^{R}$ \\
\hline Ciprofloxacin & 5 & $0 \pm 0^{R}$ \\
\hline Clindamycin & 2 & $0 \pm 0^{R}$ \\
\hline Doxycycline* & 30 & $0 \pm 0^{R}$ \\
\hline Enrofloxacin* & 5 & $0 \pm 0^{R}$ \\
\hline Erythromycin & 15 & $0 \pm 0^{R}$ \\
\hline Florfenicol $^{*}$ & 30 & $0 \pm 0^{R}$ \\
\hline Furazolidone & 30 & $21 \pm 0^{\mathrm{s}}$ \\
\hline Kanamycin & 30 & $0 \pm 0^{R}$ \\
\hline Levofloxacin & 5 & $11.5 \pm 0.71^{\mathrm{R}}$ \\
\hline Neomycin* & 30 & $10.25 \pm 0.35^{\mathrm{R}}$ \\
\hline Norfloxacin & 10 & $0 \pm 0^{\mathrm{R}}$ \\
\hline Oxacillin & 1 & $0 \pm 0^{R}$ \\
\hline Penicillin & 10 & $0 \pm 0^{R}$ \\
\hline Rifampicin & 5 & $0 \pm 0^{R}$ \\
\hline Streptomycin & 10 & $10.25 \pm 0.35^{\mathrm{R}}$ \\
\hline Sulfisoxazole* & 300 & $0 \pm 0^{R}$ \\
\hline Tobramycin & 10 & $11.25 \pm 0.35^{\mathrm{R}}$ \\
\hline
\end{tabular}

Data are presented as the mean \pm standard deviation. SSensitive; ${ }^{\mathrm{I}}$ Intermediately sensitive; Resistant.

${ }^{*}$ Antibiotics for aquaculture use (Ministry of Agriculture of China, 2013). 


\section{Discussion}

The association of $P$. shigelloides in aquaculture has been well documented with mortality of Anguilla japonica (Sugita et al., 1993), Callinectes sapidus (Marshall et al., 1996), Trionyx sinensis (Wu et al., 2004), Takifagu obscurus (Fang et al., 2005), Ostrea gigas thunberg (Gu et al., 2006), Garra rufa (Yu et al., 2009), Oreochromis niloticus (Nadirah et al., 2012; Martins et al., 2018), Ctenopharyngodon idellus (Hu et al., 2014), Andrias davidianus (Yang et al., 2014), Carassius auratus (Zhang et al., 2015), Macrobrachium rosenbergii (Liu et al., 2015), Mylopharyngodon piceus (Ye et al., 2016), Lota lota (Zhang et al., 2018) and Pelteobagrus fulvidraco (Dou et al., 2019). However, there is limited information on $P$. shigelloides isolates as causal agents for enteritis in channel catfish. In the present work, a $P$. shigelloides pathogen was isolated from channel catfish suffering from enteritis, and its phenotype, taxonomic position and antibiotic susceptibility were characterized. To our knowledge, this is the first report of a $P$. shigelloides pathogen as a causative agent for enteritis in channel catfish.

$P$. shigelloides is widely distributed in aquatic ecosystems and possesses a variety of virulence factors, including adhesive ability, hemolysins, cytotoxins, cholerae-like toxins and other exoenzymes associated with pathogenicity (Salerno et al., 2010; Edwards et al., 2019). Thus, $P$. shigelloides is a well-recognized fish opportunistic pathogen causing both intestinal and extra-intestinal diseases (Salerno et al., 2010; Zhang et al., 2019). Enteritis caused by $P$. shigelloides is probably associated with the production of these virulent factors. The intraperitoneal injection has been demonstrated as an effective challenge way to induce enteritis of fish (Xu et al., 1988; Cao et al., 2017), which is better than oral challenge and immersion exposure (Ye et al., 2000; Liu et al., 2006; Liang et al., 2007). This is probably because that the bacterial pathogen could grow in the intestinal vessel through intraperitoneal injection, release its virulent toxins which impair the permeability of vessel, damage the vessel wall and cause the erythrocytes escape, eventually resulted in the clinical signs of intestinal hyperemia and inflammation (Xu et al., 1988). Thus, the intraperitoneal injection is chosen in the challenge test. In the present study, the BD1 isolate was found to cause mortality in healthy $I$. punctatus with an LD50 value of $2.42 \times 10^{6}$ CFU $\mathrm{mL}^{-1}$. This further demonstrates the potential threat of $P$. shigelloides to channel catfish farming. Apart from the virulence of the BD1 isolate, there might be other secondary factors that induce enteritis in channel catfish such as the varieties of degradation, the misuse of feed additives, and over intensification of stocking density (Feng et al., 2019); these should also be raised as concerns.

The development of antimicrobial resistance in $P$. shigelloides is a matter of concern (Ekundayo et al., 2020). For example, P. shigelloides isolate from diseased $T$. sinensis exhibited resistance to aminoglycosides, amphenicols and tetracycline antimicrobials (Wu et al., 2004), P. shigelloides isolate from diseased Silurus asotus showed resistance to amphenicols and tetracycline antibiotics (Abdelhamed et al., 2018). In our study, isolate BD1 also developed multiple resistances to aminoglycosides, amphenicols, quinolones, tetracyclines and sulfonamides drugs used in fish farming regions, suggesting that the outbreak of this disease may have resulted from the abuse of antibiotics.

In conclusion, the present study for the first time reports a $P$. shigelloides isolate as a causal agent for enteritis in $I$. punctatus. The pathogenicity of the BD1 isolate supports this infection as a potential threat in channel catfish farming.

\section{Acknowledgements}

This work has been financially supported by Earmarked Fund for Sci-Tech Fund of Jiangsu Vocational College of Agriculture and Forestry (No. 2020kj060), Earmarked Fund for Jiangsu Modern Agricultural Industry Technology System (No. JATS [2019] 391), and SciTech Innovation Team Fund of Jiangsu Vocational College of Agriculture and Forestry (No. 110751269).

\section{References}

Abdelhamed H., Ozdemir O., Tekedar H.C., Arick M.A., Hsu C.Y., Karsi A. and M.L. Lawrence, 2018. Complete genome sequence of multidrug-resistant Plesiomonas shigelloides strain MS-17-188. Genome Announcements, 6(18): e00387-18. DOI: 
10.1128/genomeA.00387-18

Altwegg M. and J. Zollinger-Iten, 1987. Identification of Enterobacteriaceae, Aeromonas spp. and Plesiomonas shigelloides with the ATB 32GN system. Journal of Microbiological Methods, 7(2): 103-109. DOI: 10.1016/0167-7012(87)90030-3

Cao H., An J., Ou R., Lu L., Ai X. and Y. Yang, 2017. Enterobacter aerogenes: an emerging pathogen for enteritis in farmed channel catfish Ictalurus punctatus. Israeli Journal of Aquaculture-Bamidgeh, 69: 1370.

Cao H., Yang X., Gao P., Li Y., Zhang S. and L. Deng, 2007. Preliminary study of the pathogens isolated from bacterial septicaemia syndrome of sturgeons. Freshwater Fisheries, 37(2): 53-56. DOI: 10.3969/j.issn.1000-6907.2007.02.014

Chen Z., Liao H., Yang J., Cao X., Hu P., Ye Q. and X. Pei, 2012. Establishment of a real-time PCR with EVAGreen dye for the detection of Plesiomonas shigelloides. Modern Preventive Medicine, 39(23): 6234-6237. DOI: CNKI:SUN:XDYF.0.2012-23-056

Dou P., Wang L., Zhang H. and Y. Zheng, 2019. Molecular identification and drug resistance analysis of Plesiomonas shigellode isolated from fish. Biotechnology Bulletin, 35(11): 118-123. DOI: 10.13560/j.cnki.biotech.bull.1985.2019-0349

Edwards M.S., McLaughlin R.W., Li J., Wan X., Liu Y., Xie H., Hao Y. and J. Zheng, 2019. Putative virulence factors of Plesiomonas shigelloides. Antonie van Leeuwenhoek, 112: 1815-1826. DOI: $10.1007 /$ s10482-019-01303-6

Ekundayo T.C. and A.I. Okoh, 2020. Antimicrobial resistance in freshwater Plesiomonas shigelloides isolates: implications for environmental pollution and risk assessment. Environmental Pollution, 257: 1-12. DOI: 10.1016/j.envpol.2019.113493

Fang P., Chen H. and C. Huang, 2005. Sensitivity tests of pathogenic bacteria found in obscure puffer Fugu obscurus to several drugs. Fisheries Science, 24(7): 1-3. DOI: 10.16378/j.cnki.1003-1111.2005.07.001

Feng Y., Duan J., Huang X., Wang K., Deng Y., Geng Y., Ouyang P. and D. Chen, 2019. Pathological study on fulminant hemorrhagic ulcer syndrome of Ictalurus punctatus. Journal of South China Agricultural University, 40(1): 65-71. DOI: 10.7671/j.issn.1001-411X.201804013

Geng Y., Wang K., Chen D. and X. Huang, 2006. Isolation, identification and phylogenetic analysis of a pathogenic bacterium in channel catfish. Acta Microbiologica Sinica, 46(4): 649-652. DOI: $10.13343 /$ j.cnki.wsxb.2006.04.029

Gu W. and R.E. Levin, 2006. Quantitative detection of Plesiomonas shigelloides in clam and oyster tissue by PCR. International Journal of Food Microbiology, 111(1): 81-86. DOI: 10.1016/j.ijfoodmicro.2006.05.005

Hu Q., Lin Q., Shi C., Fu X., Li N., Liu L. and S. Wu, 2014. Isolation and identification of a pathogenic Plesiomonas shigelloides from diseased grass carp. Acta Microbiologica Sinica, 54(2): 229-235. DOI: 10.13343/j.cnki.wsxb.2014.02.012

Huang X., Wu C., Deng Y., Wang K., Geng Y. and J. Zhao, 2010. Pathohistological observation of Ictalurus punctatus infected with Aeromonas veronii. Chinese Veterinary Science, 40(7): 738-742. DOI: 10.16656/j.issn.1673-4696.2010.07.022

Huang J., Huang Y., Hu D., Luo H., Shi J., Peng M., Xuan J., Tan L., Teng Z. and K. Zeng, 2013. Characterization of white plastron disease pathogens and detection of six known virulence genes in Truogx sinensis. Acta Hydrobiologica Sinica, 5: 844-854. DOI: $10.7541 / 2013.108$

Khardori N. and V. Fainstein, 1988. Aeromonas and Plesiomonas as etiological agents. Annual Review of Microbiology, 42(1): 395-419. DOI: 10.1146/annurev.mi.42.100188.002143

Liang W., Chen M., Yu X., Li L., Lei A., Chen H., Xu Z., Gan X. and W. Huang, 2007. Isolation and identification of causative pathogen for enteric septicemia of catfish (ESC). Southwest China Journal of Agricultural Sciences, 25(5): 1124-1129. DOI: 10.16213/j.cnki.scjas.2007.05.056

Liu Z., Ke X., Lu M., Gao F., Cao J., Zhu H. and M. Wang, 2015. Identification and pathological observation of a pathogenic Plesiomonas shigelloides strain isolated from cultured tilapia (Oreochromis niloticus). Acta Microbiologica Sinica, 55(1): 96-106. DOI: 10.13343/j.cnki.wsxb. 20140165 
Liu T., Wang C. and C. Chen, 2006. Isolation and identification of pathogenic bacteria from channel catfish, Ictalurus punctatus. Journal of Huazhong Agricultural University, 25(5): 550-554. DOI: 10.13300/j.cnki.hnlkxb.2006.05.021

Marshall D.L., Kim J.J. and S.P. Donnelly, 1996. Antimicrobial susceptibility and plasmid-mediated streptomycin resistance of Plesiomonas shigelloides isolated from blue crab. Journal of Applied Bacteriology, 81(2): 195-200. DOI: 10.1111/j.13652672.1996.tb04500.x

Martins A.F.M., Fontana H., Moreira B.M. and R.R. Bonelli, 2018. Draft genome sequence of a tetracycline-resistant Plesiomonas shigelloides strain isolated from aquaculture-reared tilapia. Microbiology Resource Announcements, 7(2):1-2. DOI: 10.1128/MRA.00832-18

Ministry of Agriculture and Rural Affairs of China, 2019. China Fishery Statistical Yearbook. China Agriculture Press, Beijing. 25 pp.

Ministry of Agriculture of China, 2013. The First Catalogue of Veterinary Prescription Drugs. China Animal Health, 15(11): 81-83.

Mohammed H.H. and E. Peatman, 2018. Winter kill in intensively stocked channel catfish (Ictalurus punctatus): Coinfection with Aeromonas veronii, Streptococcus parauberis and Shewanella putrefaciens. Journal of Fish Diseases, 41(9):1-9. DOI: $10.1111 /$ jfd. 12827

Nadirah M., Ruhil H.H., Jalal K.C. and M. Najiah, 2012. Occurrence of Plesiomonas shigelloides in cultured red hybrid tilapia (Oreochromis niloticus) from tropical rivers, east coast Malaysia. Pakistan Journal of Biological Sciences, 15(12): 600-603. DOI: 10.3923/pjbs.2012.600.603

Orozova P., Sirakov I., Petkov I., Crumlish M. ang B. Austin, 2012. Recovery of Aeromonas hydrophila associated with bacteraemia in captive snakes. FEMS microbiology letters, 334(1): 22-26. DOI: 10.1111/j.1574-6968.2012.02613.x

Olsson J.C., Westerdahl A., Conway P.L. and S. Kjelleberg, 1992. Intestinal colonization potential of turbot (Scophthalmus maximus)-and dab (Limanda limanda)associated bacteria with inhibitory effects against Vibrio anguillarum. Applied and Environmental Microbiology, 58(2): 551-556. DOI: 10.1128/AEM.58.2.551-556.1992

Salerno A., Čižnár I., Krovacek K., Conte M., Dumontet S., González-Rey C. and V. Pasquale, 2010. Phenotypic characterization and putative virulence factors of human, animal and environmental isolates of Plesiomonas shigelloides. Folia Microbiologica, 55(6): 641-647. DOI: $10.1007 / \mathrm{s} 12223-010-0104-8$

Spielmann H., Genschow E., Liebsch M. and W. Halle, 1999. Determination of the starting dose for acute oral toxicity ( $\mathrm{LD}_{50}$ ) testing in the up and down procedure (UDP) from cytotoxicity data. Alternatives to Laboratory Animals, 27: 957-966. DOI: $10.1177 / 026119299902700609$

Sugita H., Nakamura T. and Y. Deguchi, 1993. Identification of Plesiomonas shigelloides isolated from freshwater fish with the microplate hybridization method. Journal of Food Protection, 56(11): 949-953. DOI: 10.4315/0362-028X-56.11.949

Wang X., Xu L., Cao H., Wang J. and S. Wang, 2013. Identification and drug sensitivity of a Plesiomonas shigelloides isolated from diseased sturgeons. Acta Microbiologica Sinica, 53(7): 723-729. DOI: 10.13343/j.cnki.wsxb.2013.07.008

Wu H. ang J. Xue, 2004. Pathogens of haemorrhagic intestinal necrosis in soft-shelled turtle (Trionyx sinensis) and their drug sensitivity. Chinese Journal of Veterinary Science, 24(4):343-345. DOI: $10.16303 /$ j.cnki.1005-4545.2004.04.011

Wu L., Zhang D., Wang G. and Z. Sun, 2000. The main diseases and prevention and treatment of Ictalurus punctatus. Freshwater Fisheries, 30(10):35-37. DOI: $10.3969 /$ j.issn.1000-6907.2000.10.016

Xie H., Wei W., Wang K., Liu T., He S., Yang Q. and J. Liu, 2019. Genome sequencing and comparative genomics analysis of Stenotrophomonas maltophilia isolated from Ictalurus punctatus. Journal of Fisheries of China, 43(7): 1635-1646. DOI: $10.11964 /$ jfc. 20180811387

Xu B., Ge R. and M. Xiong, 1988. Pathogenetic investigation of the enteritis of the grass carp (Ctenopharyngodon idellus). Acta Hydrobiologica Sinica, 12(4): 308-315. DOI: 
doi:http://ir.ihb.ac.cn/handle/152342/6058

$\mathbf{X u}$ T., 2008. Isolation and screening of bacteria produced proteinase from gastrointestinal tract of Japanese sea bass. Journal of Anhui Agricultural Sciences, 36(11): 4544-4546. DOI: $10.3969 /$ j.issn.0517-6611.2008.11.075

Yang X., Zeng L., Li R., Zhang H., Fan Y. and Y. Zhou, 2014. Isolation and identification of Plesiomonas shigelloides from diseased Andrias davidianus. Journal of Hydroecology, 35(1): 91-95. DOI: 10.15928/j.1674-3075.2014.01.018

Ye X., Gu J., Yang G., Luo Y., 2000. The pathogen and control of Aeromonas sobria disease of Rana catesbiana. Journal of Shanghai Fisheries University, 9(1): 78-80.

Ye J., Liu X., Wang X., Xu H., Shen W., Gao M. and X. Zhang, 2016. Isolation and identification of pathogenic Plesiomonas shigelloides from diseased black carp Mylopharyngodon piceus. Oceanologia Et Limnologia Sinica, 47(3): 633-639. DOI: 10.11693/hyhz20160300049

Yu H., He Z., Yan B., Yang G., Hu., J. and M. Zhou, 2009. Identification of Plesiomonas shigelloides and Aermonas schuberti from doctor fish (Garra rufa) and antibiotics sensitivity. China Animal Health Inspection, 26(7): 37-39.

Zeng L., Xu J., Li Y., Wang Y., Xiao Y., Fan Y. and Y. Zhou, 2009. Isolation and identification of channel catfish (Ictalurus punctatus) hemorrhage reovirus. Chinese Journal of Virology, 25(6): 460-466. DOI: 10.1016/j.elecom.2008.10.019

Zhang T., Gan J., Chen J., Zhou J., Zhang L. and L. He, 2019. Morphological characteristics and electrophoretic analysis of two kinds of isozymes from Ictalurus punctatus. Chinese Fishery Quality and Standards, 9(6): 57-64. DOI: 10.3969/j.issn.20951833.2019.06.007

Zhang M., Hu A., Cheng Z., Jiang H. and M. Weng, 2019. Isolation, identification and drug resistance analysis of Plesiomonas shigelloides from hybrid sturgeon. China Animal Husbandry \& Veterinary Medicine, 46(1): 264-270. DOI: 10.16431/j.cnki.16717236.2019.01.031

Zhang X., Yang X., Li X., Li Z. and B. Shang, 2018. Isolation, identification and drug sensitivity of pathogen Plesiomonas shigelloides in burbot Lota lota. Fisheries Science, 37(4): 533-538. DOI: 10.16378/j.cnki.1003-1111.2018.04.016

Zhang P., Zhu A., Hu X., Lan Y., Li X., Shen X. and A. Lv, 2015. Isolation, identification and antibiotic susceptibility testing of Plesiomonas shigelloides from goldfish. Fisheries Science, 34(6): 375-379. DOI: 10.16378/j.cnki.1003-1111.2015.06.007

Zhu Y., Gong C., Xue R., Cao G., Wei Y., 2001. Isolation and characteristics of Plesiomonas shigelloides from tissue of Eriocheir sinensis. Chinese Journal of Microecology, 13(5): 263-264. DOI: 10.3969/j.issn.1005-376X.2001.05.006 